\title{
SALARIOS, PRECIOS Y NIVEL DE VIDA EN MENDOZA DURANTE LA TRANSFORMACIÓN VITIVINÍCOLA (1890-1914)
}

\author{
Wages, prices, and living standards in Mendoza during the wine industry \\ transformation (1890-1914)
}

\section{Beatriz Bragoni* y Patricia Olguín**}

\section{Resumen}

Este trabajo estudia el impacto del crecimiento económico de Mendoza en los salarios de los sectores populares entre fines del siglo XIX y 1914. Sobre la base de fuentes homogéneas y confiables depositadas en archivos públicos (presupuestos provinciales, libros de jornales de Bodegas Arizu) y bibliografía especializada, se ofrecen series temporales para un Índice de Costo de Vida y salarios reales de empleados públicos de baja y mediana calificación (peón de policía, portero y escribiente) y del peón de viña. Los resultados obtenidos indican que los salarios reales aumentaron levemente, aunque de manera diferenciada entre categorías, y que presentaron importantes oscilaciones vinculadas a la coyuntura económica. Así, disminuyeron durante la recesión vitivinícola de principios de siglo y, más aún, durante el proceso inflacionario iniciado en 1907 bajo el impulso del precio de los alquileres. La contrastación de estas evidencias con las aportadas por los estudios disponibles para Buenos Aires, da cuenta de un menor ascenso relativo en los salarios reales de los trabajadores mendocinos.

$$
<\text { Salarios }><\text { Precios }><\text { Índice de costo de vida }><\text { Vitivinicultura }>
$$

\begin{abstract}
This paper aims to analize the impact of the economic growth of Mendoza in the wages of popular sectors between the late nineteenth century and 1914. On the basis of homogeneous and reliable sources deposited in public archives (provincial budgets, wages books of Bodegas Arizu), and specialist literature. This paper offers time series for a Cost of Living Index and real wages of low and medium public employee grades (low-level policeman, porter and clerk), and vineyard employees. The results indicate that real wages increased slightly, although differentially between categories, and presented significant fluctuations linked to the economic situation. Thus, wages fell during the recession of wine industry at the beginning of the twentieth century and, even more, during the inflationary process initiated in 1907, under the impulse of rent prices. The contrast of this evidence with those provided by the studies available for Buenos Aires, reveals a lower relative rise in real wages of workers from Mendoza.
\end{abstract}

$<$ Wages $><$ Prices $><$ Cost of living index $><$ Viticulture $>$

Recibido: 20/05/2016 // Aceptado: 31/08/2016

\footnotetext{
* Doctora en Historia. UBA/CONICET. bbragoni@mendoza-conicet.gob.ar

** Doctora en Historia. UNICEN/CONICET. polguin@mendoza-conicet.gob.ar
} 


\section{Introducción}

Este trabajo estudia el impacto del crecimiento económico de Mendoza en los salarios de los sectores populares entre fines del siglo XIX y 1914, es decir durante el período comúnmente conocido como del despegue y consolidación de la agroindustria vitivinícola. Ante la escasez de estudios cuantitativos, se ha creído conveniente avanzar en la construcción de evidencia empírica que contribuya a mejorar la comprensión de la desigualdad social en el largo plazo. A partir del examen de información estadística, se analiza la composición y evolución de los recursos públicos provinciales (indicador del Producto Bruto Interno). Igualmente, se construye una canasta de subsistencia para una familia urbana y series de índices de precios de bienes y servicios de consumo popular, que permiten calcular un Índice de Costo de Vida para el período 1895-1914. Este último es utilizado para analizar los cambios en el poder adquisitivo de los salarios de tres categorías de empleados públicos de baja y mediana calificación (peón de policía, portero y escribiente) y del peón de viña de una empresa líder, Bodegas Arizu ${ }^{1}$.

La literatura académica refleja el interés de los investigadores por describir y explicar la "transformación vitivinícola", y una preocupación mucho menor por conocer los cambios que ésta conllevó en la desigualdad social en términos de niveles de ingreso. En relación con la primera cuestión, las pesquisas han abordado la concurrencia de factores que gravitaron en el "boom" vitivinícola, el cual distingue el arsenal de estímulos institucionales, las iniciativas promovidas por las dirigencias políticas, y el protagonismo del empresariado local (nativo e inmigrante), cuyo accionar estuvo sujeto a condiciones favorables regidas primordialmente por la protección arancelaria, el ferrocarril y el exponencial aumento de consumidores en las áreas pampeanas (y extrapampeanas). Los trabajos han descripto el proceso por el cual los grandes y medianos establecimientos industriales localizados en las zonas productoras (principalmente, los oasis de riego de Mendoza y San Juan) enviaban el vino a granel por ferrocarril hacia las provincias de Buenos Aires, Santa Fe y Córdoba, desde donde era distribuido por casas o representantes a los comercios minoristas. También han mostrado que el consumo per cápita aumentó de la mano de inmigrantes italianos, españoles y franceses, y del crecimiento poblacional; según los censos nacionales, el número de habitantes en Mendoza pasó de 65.413 en 1869 a 116.036 en 1895, y a 277.535 en 1914. Los alcances del cambio estructural, por el cual el comercio de ganado y la producción de cereales y harinas perdieron peso relativo en favor de la vitivinicultura industrial, han sido precisados sobre la base de evidencias estadísticas firmes en relación con la progresiva ampliación de la superficie cultivada con vid, la introducción de nuevas cepas, la escasa diversificación de los usos de la uva y el ascenso

\footnotetext{
Las empresas Bodegas Arizu (1908), junto con Bodegas y Viñedos Giol (1911) y Domingo Tomba (1911), fueron las primeras sociedades anónimas constituidas en la agroindustria vitivinícola argentina. Estas firmas, gracias a un proceso de integración vertical que comprendía las etapas agrícola, industrial y comercial, eran las que elaboraban los mayores volúmenes de vino de mesa en el país. Tenían su casa central, y más tarde sucursales y oficinas de venta, fuera de la provincia, y marca propia. Aunque las series de salarios relativas a la empresa no puedan ser transferidas al conjunto del sector industrial, se consideran indicativas de las tendencias de firmas líderes con lo cual resulta de interés cotejarlas con los salarios del sector público.
} 
de la elaboración y despacho de vinos de mesa, entre otras variables. Este proceso expansivo, cuya tendencia alcista sólo fue alterada por accidentes climáticos, plagas de la vid y "planes de emergencia" gubernamentales implementados para adecuar la oferta a la demanda, gravitó no sólo en el aumento de la capacidad instalada de los establecimientos industriales o "fábricas de vino", sino también en la emergencia de una discreta cadena de eslabonamientos productivos inducidos o derivados de la actividad vitivinícola. $^{2}$ La vinícola se convirtió tempranamente en la principal industria de Mendoza, tanto por el número de establecimientos como por el monto de los capitales invertidos. La información disponible también ha permitido apreciar las modificaciones en las estrategias de comercialización de las bodegas, y precisar su incidencia en los nuevos estilos de gestión empresarial, en particular en las firmas más concentradas del sector. $^{3}$

El estado del conocimiento da cuenta de los matices que exhibió dicho proceso, al enfatizar las "deficiencias" o debilidades de la flamante agroindustria que se hicieron evidentes en las crisis de 1900-1903 y 1914-1918 a raíz de la caída de los precios del vino $^{4}$. Sin embargo, los estudios disponibles arrojan poca luz sobre los altibajos ocurridos al interior de las etapas expansivas y recesivas, generalmente ligados a los instrumentos y resultados de la política económica (nacional y provincial). Es necesario indagar las repercusiones que la expansión monetaria y el encarecimiento del oro (que derivaron en la crisis financiera de 1890) tuvo en el despegue inicial (1880-1890); conviene examinar, además, el modo en que el ordenamiento fiscal, monetario y cambiario habilitó la reactivación económica posterior (1895-1899); igualmente relevante es atender a las consecuencias que nuevas emisiones monetarias, desórdenes fiscales y cambiarios, y el aumento y concentración de la población en los centros urbanos tuvieron en el crecimiento económico de principios del siglo XX, y en su progresiva erosión causada por la inflación (1905-1913). Este trabajo pretende contribuir a avanzar en esa dirección.

Por otra parte, y en relación con la segunda cuestión, las interpretaciones más difundidas en torno a las pujas distributivas que vigorizaron el desarrollo agroindustrial en el cambio de siglo, enfatizaron dos aspectos igualmente relevantes: 1) La restricción relativa de los beneficios del crecimiento económico entre los "sectores populares", urbanos y/o rurales; 2) Las presiones ejercidas en el mercado de vinos por las corporaciones empresariales y los grupos más concentrados del sector (grandes bodegueros y comerciantes) en detrimento de los menos integrados (pequeños y medianos viticultores y bodegueros $)^{5}$. El primer aspecto ha constituido un tópico regular de las versiones menos optimistas del proceso de transformación agroindustrial. Generalmente ceñidos a develar la correlación entre modernización económica y las condiciones de vida de los sectores populares, dichos estudios han estimado un "salario mínimo de subsistencia" de familias urbanas para 1893, cuya elaboración destacó el dinamismo del mercado de trabajo, la transitoriedad en las ocupaciones y la insuficiencia del salario

\footnotetext{
2 Véase en particular, Balán y López (1977); Balán (1978); Richard Jorba y Pérez Romagnoli (1994); Richard Jorba (1998); Coria (2006) y (2010).

3 Véase, entre otros, Bragoni (1999); Mateu (2002); Olguín (2013a); Olguín (2013b).

${ }^{4}$ Barrio de Villanueva (2002) y Olguín (2012).

5 Olguín (2012) y Olguín y Mellado (2010).
} 
de los trabajadores no especializados para cubrir las necesidades básicas del grupo familiar, lo cual forzó a esposas, hijos, parientes y arrimados a contribuir a engrosar los recursos de la unidad doméstica; de manera complementaria, se ha prestado atención a las estrategias familiares en la organización del trabajo rural (Prieto y Chorén, 1990 y 1991-1992). Por su parte, y más recientemente, otros especialistas se dedicaron a evaluar la relación entre remuneraciones y precios de artículos de consumo popular entre 1890 y 1918 (realizados sobre la base de fuentes primordialmente secundarias que disponían de información sólo para algunos años), y postularon una reducción en la capacidad de compra de los salarios de peones y jornaleros ${ }^{6}$. Un análisis sobre la evolución de los precios locales entre 1895 y 1914 estimó un aumento de un $25 \%$ en el nivel general de precios mayoristas (de alimentos, leña y papel), el cual habría estado influido por la emisión de letras de tesorería por parte del Estado provincial iniciada en 1892 y que se prolongó hasta 1925 (Coria, 2004: 6). Por otra parte, el segundo aspecto, relativo a la distribución del ingreso en la cadena vitivinícola durante el período 1895-1914, ha sido menos explorado; por lo cual, no contamos con estimaciones sobre la proporción en que los crecientes ingresos provenientes de las ventas de vino se distribuyeron entre empresarios (viñateros, bodegueros y comerciantes) y trabajadores.

De modo que estas "miradas" relativas a los beneficios y perjuicios del proceso de transformación agroindustrial se han basado en datos fragmentarios, discontinuos y heterogéneos en relación con las fuentes de las que proceden. El presente trabajo pretende contribuir a llenar esas lagunas, estimulado por el renovado interés de la historiografía por estudiar la desigualdad social en el largo plazo, principalmente en Europa y América, a partir de la construcción de series continuas de salarios reales, susceptibles de comparación internacional. ${ }^{7}$ La mayor parte de la literatura sobre Argentina se ha centrado entre el período colonial y mediados del siglo XIX ${ }^{8}$, de modo que se dispone de pocos antecedentes sobre el período 1895-1914. La investigación de Cortés Conde (1979) sobre un índice de alimentos (pan y carne) y salarios reales del peón de policía y el obrero industrial para Buenos Aires entre 1882 y 1912, ha constituido un referente para las contribuciones posteriores. Campi (2004) y Correa Deza y Campi (2009) reconstruyeron la evolución del salario real del peón del azúcar en Tucumán, articulando dos investigaciones desarrolladas con fuentes y metodologías diferentes: la primera, sobre el período 1881-1893 y, la segunda, sobre 1904-1927; para lo cual, construyeron dos índices de precios de alimentos. Por su parte, Cuesta (2012) construyó series de precios minoristas para la ciudad de Buenos Aires a partir de libros de contabilidad de organismos oficiales disponibles en archivos públicos, y una canasta de consumo de una familia obrera, apoyándose en información aportada por el dirigente socialista Alfredo Palacios; los mismos le permitieron calcular el único Índice de Costo

\footnotetext{
${ }^{6}$ Richard Jorba (2012; 444). Las conclusiones del autor en relación con las fuentes consultadas, y en especial con la ausencia de serie de precios y salarios que permitan inferir interpretaciones fundadas empíricamente, han sido advertidas oportunamente. Véase, Djenderedjian (2013).

7 Véase, a modo de ejemplo, el estudio clásico de Williamson (1999), y Allen (2001). Para países latinoamericanos, Bértola, Camou y Porcile (1999); Bértola Flores (2005); Arroyo Abad, Davies y van Zanden (2011) y Arroyo Abad (2013).

8 Véase, Gelman y Santilli (2014, 2015 y 2016) para Buenos Aires, Djenderedjian y Martirén (2015) para Santa Fe, y Parolo (2015) para Tucumán.
} 
de Vida disponible para el período 1850-1914. Recientemente, Correa Deza y Nicolini (2014) calcularon dos índices de precios para catorce provincias del país para algunos años entre 1903 y 1912, sobre la base de información contenida en los Boletines del Departamento Nacional del Trabajo: en el primero, replicaron el índice de alimentos calculado por Cortés Conde para un espacio geográfico más amplio; en el segundo, agregaron otros seis alimentos que figuraban entre los más consumidos por las clases populares.

En función de las metodologías validadas por los historiadores económicos, y frente a la escasa e insuficiente información estadística producida por el Estado provincial ${ }^{9}$, se ha creído conveniente avanzar en la construcción de series temporales de variables e indicadores cuantitativos sobre la base de fuentes homogéneas y confiables. Para ello, se recopilaron series de recursos tributarios, salarios públicos de los presupuestos provinciales transcriptos en los Registros Oficiales de la Provincia Mendoza y salarios privados contenidos en los libros de jornales de Bodegas Arizu, alojados en el Archivo General de la Provincia. Por su parte, en el abordaje sobre precios, atendiendo a las dificultades ya señaladas sobre la ausencia de índices confeccionados por las agencias estatales, se examinó la composición de una canasta de bienes y servicios consumidos por una familia urbana procedente de las investigaciones pioneras de Prieto y Chorén (1990 y 1991-1992) y las series de precios mayoristas de alimentos y leña elaboradas por Coria (2004). A partir de ellas, y de información sobre vivienda y vestimenta extraída de los presupuestos provinciales, se avanzó en la construcción de un Índice de Costo de Vida que permitió estimar salarios reales y determinar si éstos eran susceptibles de cubrir el costo de una canasta de subsistencia.

El artículo se divide en dos partes. La primera aborda la transformación económica y social de Mendoza poniendo el foco en los recursos públicos como un indicador del crecimiento de la producción, a fin de identificar coyunturas expansivas y recesivas. Luego, se explicitan los procedimientos utilizados para construir la canasta básica de consumo y el Índice de Costo de Vida para el período 1895-1914. En la segunda parte, se presentan y analizan las series de salarios nominales de los trabajadores y la estimación de los salarios reales correspondientes. Por último, se exponen los principales resultados que surgen de la evidencia construida.

\section{Apuntes sobre la transformación económica y social: los cambios en el costo de vida}

El crecimiento exponencial de la elaboración y venta de vinos tuvo un fuerte impacto en las finanzas públicas al proveer de liquidez a la economía mendocina y contribuir, de manera sustancial, a la expansión del gasto público (entre los principales rubros, se encontraban los salarios); aunque éste también fue financiado por aportes del Estado nacional y empréstitos interiores y exteriores. De este modo, en la década de 1880 los principales ingresos provenían de los bienes raíces, así como de la ganadería

\footnotetext{
9 Si bien la Oficina de Estadísticas fue creada en los años ochenta, su reducida planta administrativa (tres empleados estables) limitó las referencias sobre salarios y precios sólo para algunos años $(1888,1903)$; la situación se modificó luego de 1910 para cuando los Anuarios provinciales consignaron mayores detalles sobre escalas salariales y precios.
} 
comercial (patentes, en su mayor parte aportadas por la carne y el derecho de invernada). Sin embargo, en el decenio siguiente, sobre todo desde 1895, el impuesto a los frutos y alcoholes (que incluía al vino) se convirtió en la principal fuente de recursos. Más aun, desde 1905 los impuestos al vino aportaron alrededor del 50\% de las rentas, mientras que la contribución directa, las patentes fiscales y el papel sellado disminuyeron su participación en la recaudación total.

En suma, y de acuerdo a las fuentes oficiales, el Estado provincial adquirió una relativa autonomía financiera gracias al esquema tributario. No obstante, convendría tener en cuenta las evidencias aportadas por $\mathrm{Llach}^{10}$, la cuales subrayan los aportes del Tesoro Nacional relativos a 1889 y 1890 (m\$n 550.000 cada año), y a 1903 y 1904 (m\$n 10.000 cada año) en concepto de bancos, títulos, etc. ${ }^{11}$; en tanto, las estadísticas oficiales de Mendoza sólo consignan las subvenciones recibidas en 1914 (representan el $1 \%$ de los recursos totales). En la coyuntura crítica de 1889-1890, los fondos nacionales prácticamente igualaron a los recursos fiscales de Mendoza. A su vez, el endeudamiento público y la emisión de letras de tesorería fueron la principal vía utilizada para financiar el déficit fiscal, sobre todo entre 1892 y 1914; de ello dan cuenta los servicios de deuda previstos en los presupuestos provinciales.

En el Gráfico 1 se presentan las series temporales de recursos propios, totales y per cápita efectivamente percibidos, expresadas en pesos oro (\$oro), a fin de evitar las distorsiones producidas por la desvalorización/valorización del papel moneda (peso moneda nacional o, en forma abreviada, $\mathrm{m} \$ \mathrm{n})$.

Gráfico 1. Recursos tributarios del Estado de Mendoza, valor total y per cápita, 1892-1914

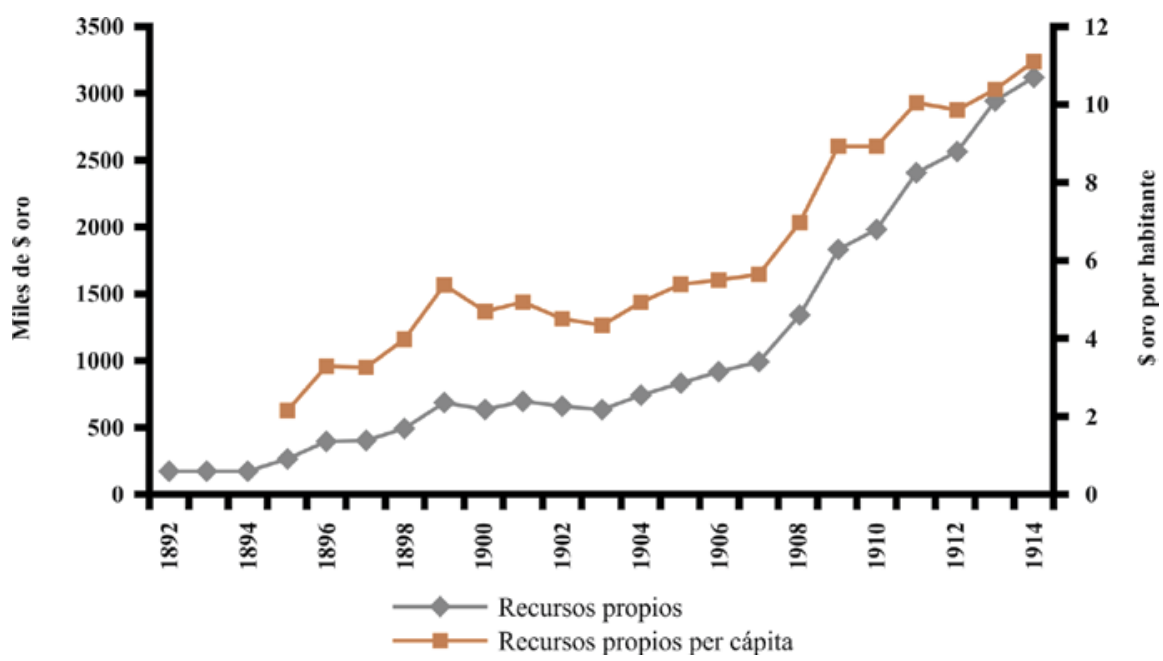

Fuente: Elaboración propia en base a Anuario Estadístico de Mendoza para 1914 y Olarra Jiménez (1968; 182-183).

${ }^{10}$ Llach (2007), a partir de información proveniente de los Anuarios de Comercio y Navegación de la Dirección General de Estadísticas. Agradecemos al autor las referencias sobre Mendoza.

${ }^{11}$ Interesa señalar que los aportes del bienio 1889-1890 coinciden con la creación de los bancos garantidos. Véase, Mateu (1995); Gerchunoff, Rocchi, y Rossi (2008); Meisel Roca (2008). 
Las trayectorias de ambas variables permiten advertir la tendencia creciente ${ }^{12}$, así como individualizar subperíodos con comportamientos específicos, ya mencionadas en la introducción: 1892-1894, de estancamiento, que coincidió con la crisis financiera nacional de 1890; 1895-1899, de recuperación; 1900-1903, de crisis vitivinícola ${ }^{13}$; $1904-$ 1913 , de vigoroso crecimiento que adoptó un ritmo todavía mayor a partir de 1908. Esta evolución habilita a considerar a los recursos propios efectivamente percibidos (que en su mayoría eran de origen tributario) como una variable proxy del Producto Bruto Interno provincial.

Conviene ahora analizar los cambios en el costo de vida de los sectores populares el en estas coyunturas. Para ello, construimos un Índice de Costo de Vida siguiendo la metodología clásica de Laspeyres, que requiere, en este caso, conocer la canasta de consumo de las familias en un momento determinado, a fin de establecer la ponderación de cada artículo en el gasto familiar, y la serie de los índices de precios de los mismos. Los supuestos en los cuales se basa este método, que ha sido utilizado por Allen (2001) para calcular índices de precios en Europa entre la Edad Media y la Primera Guerra Mundial, han sido criticados. Dobado-González (2015), en particular, cuestiona que las cantidades consumidas de cada bien permanezcan fijas durante todo el período y considera que el precio de los commodities es un mejor indicador para el período colonial. ${ }^{14}$ Este criterio ha sido aplicado para Tucumán, tomando el precio del azúcar como deflactor de los salarios nominales del peón azucarero, y comparando su evolución con dos índices de precios de alimentos y leña para 1881-1893 y de alimentos (aunque éstos son más numerosos) para 1904-1927. En el primer período se nota una correspondencia entre ambos indicadores pero, en el segundo, la misma se desdibuja, atento a que los mercados se vuelven más complejos (Correa Deza y Campi, 2009; 15). Como se verá más adelante, y atendiendo a las similitudes entre la agroindustria azucarera y la vitivinícola, este trabajo demuestra que el precio de la uva (que tenía la misma tendencia que el vino) no es un buen indicador para deflactar variables nominales para el período estudiado.

La canasta de bienes y servicios ha sido elaborada en base al estudio realizado por Prieto y Chorén (1990), el cual se valió de información proporcionada por la Dirección General de Inmigraciones para 1893, y a los presupuestos provinciales. La canasta, que representa el consumo mínimo de subsistencia de una familia de cuatro integrantes (los cónyuges y dos hijos) para $1893^{15}$, incluye los siguientes bienes y servicios: seis

\footnotetext{
${ }^{12} \mathrm{La}$ brecha entre ellas se reduce hacia el final del período por el aumento poblacional que conllevó la llegada masiva de inmigrantes.

${ }^{13}$ El primer momento crítico de la industria se produjo en el trienio 1901-1903, durante un periodo de iliquidez de la economía nacional que ocasionó una contracción de la demanda de vinos, profundizada por las debilidades de la agroindustria (Barrio, 2002; 330). Este traspié fue superado gracias a la recuperación del consumo, a una reforma legal que incluyó la eliminación de un impuesto interno nacional al vino expedido, a la sanción de una ley nacional de vinos que rigió los aspectos técnicos de la agroindustria y al control estatal de calidad (Olguín, 2009; 19-20).

${ }^{14}$ La controversia se desarrolla en la Revista de Historia Económica-Journal of Iberian and Latin American Economic History, Vol. 33, Issue 1, Marzo 2015.

${ }^{15}$ Este número responde a que, según el Segundo Censo Nacional de Población de 1895, el promedio de
} 
alimentos (pan, carne vacuna, azúcar, yerba, maíz majado, grasa animal), un bien utilizado para combustible e iluminación (leña de algarrobo), el alquiler de un cuarto en la Ciudad de Mendoza (casa para comisaría) y vestimenta (uniformes de invierno y verano para soldados, cabos y agentes de policía de la Capital). Otras investigaciones, con el propósito de realizar comparaciones internacionales, han traducido los consumos en calorías. ${ }^{16}$

Los consumos de cada bien y servicio, diarios y mensuales, se exponen a continuación.

Tabla 1. Canasta de subsistencia para una familia conyugal con dos hijos, 1893

\begin{tabular}{llccc}
\hline & \multirow{2}{*}{ Bienes y servicios } & \multicolumn{2}{c}{ Consumos } & \multicolumn{2}{c}{ Ponderaciones } \\
\cline { 3 - 5 } & & día & mes & \% \\
\hline \multirow{2}{*}{ Alimentos } & Carne de vaca & $2 \mathrm{~kg}$. & $60 \mathrm{~kg}$. & 19 \\
& Pan & $2 \mathrm{~kg}$. & $60 \mathrm{~kg}$. & 14 \\
& Grasa & $0,10 \mathrm{~kg}$. & $3 \mathrm{~kg}$. & 9 \\
& Yerba mate & $0,20 \mathrm{~kg}$. & $6 \mathrm{~kg}$. & 8 \\
& Azúcar & $0,25 \mathrm{~kg}$. & $7,5 \mathrm{~kg}$. & 6 \\
Comb. e iluminación & $0,20 \mathrm{~kg}$. & $6 \mathrm{~kg}$. & 4 \\
Alquiler & Maíz majado & $4 \mathrm{~kg}$. & $120 \mathrm{~kg}$. & 19 \\
Vestimenta & Leña & & $1 \mathrm{casa} / 5$ & 9 \\
& Un cuarto & & $2 \mathrm{unif} / / 12$ & 9 \\
\hline
\end{tabular}

Fuente: Elaboración propia en base a Prieto y Chorén (1990), Registros Oficiales de la Provincia de Mendoza y Leyes de Presupuesto para el período 1895-1914.

Notas: 1) Las cantidades consumidas para los bienes y servicios del rubro "Alimentos" son las consignadas por Prieto y Chorén (1990) para 1893 y corresponden al 58,5\% del total. 2) Suponemos que el precio por $\mathrm{kg}$ es un $10 \%$ más caro que el mayorista $(1000 \mathrm{~kg})$, lo cual se consignó en una de las facturas de compra. Entonces a un gasto de 0,8 pesos para 1893 y un precio de $0,018^{*} 1,10$ (suponemos que el precio es el mismo para 1893) corresponde $4 \mathrm{~kg}$. 3) La casa para comisaría en la Capital se supone que tenía cinco cuartos, ya que el precio para 4 personas de $1895(\mathrm{~m} \$ \mathrm{n} 9,6)$, que coincide con el de 1893, es consistente con el aportado por Prieto y Chorén para 6 personas $(\mathrm{m} \$ \mathrm{n} 15)$. También guarda relación con el alquiler de una pieza en los suburbios de la Ciudad de Mendoza o en los departamentos que la rodean para 4 personas $(\mathrm{m} \$ \mathrm{n}$ 8), consignado por la Memoria descriptiva y estadística de la provincia de Mendoza publicada por el Centro Comercial, Agrícola e Industrial para 1893, citada por Richard Jorba (2012; 450). 4) El gasto en vestimenta por mes se obtuvo dividiendo el costo de 2 uniformes de invierno y 2 uniformes de verano (1 para el hombre, 1 para la mujer y 1 para cada hijo) por 12 , ya que el precio para $1895(\mathrm{~m} \$ \mathrm{n} 12)$ es consistente con el consignado por la Memoria del Centro Comercial (m\$n 13,12 para 4 personas). 5) La composición de la canasta y la calidad de los bienes que la integran no cambian sustancialmente durante el período.

Cabe señalar que, teniendo en cuenta los bienes y servicios con mayor participación relativa en el costo total de la canasta para 1893, las ponderaciones resultantes por rubro son: alimentos (58\%), combustible e iluminación (4\%), vivienda

miembros de la familia, cuyo jefe era jornalero, era de 4,3 (Prieto y Chorén, 1991-1992; 134).

${ }^{16}$ Véase, a modo de ejemplo, Allen (2001), Bértola, Camou y Porcile (2009), Arroyo Abad, Davies y van

Zanden (2011), Arroyo Abad (2013), Challú y Gómez-Galvarriato (2015) y Gelman y Santilli (2016). 
(19\%) y vestimenta (18\%). ${ }^{17}$ Entre las investigaciones disponibles sobre Argentina que abordan el período $1895-1914$, sólo Cuesta $(2012 ; 166)$ obtuvo información para para sumar vivienda y vestimenta, además de la relativa a alimentos. Sobre la base de datos ofrecidos por el dirigente socialista Alfredo Palacios (1892), consideró los siguientes bienes y ponderaciones: trigo y/o pan $(27 \%)$, maíz $(7 \%)$, carne $(28 \%)$, vino $(5 \%)$, azúcar (3\%), alquiler (20\%) y ropa (10\%). De la comparación de ambas canastas surge que en Mendoza la ropa tenía mayor peso en el gasto familiar que en Buenos Aires, en detrimento de los alimentos. Asimismo, en esta última provincia, el pan y la carne representaban el 55\% del gasto total, frente al 33\% de Mendoza. Por otra parte, en los dos casos se observa una preferencia por los bienes y servicios nacionales.

Las series de índices de precios, en cambio, se confeccionaron a partir de fuentes información básica para todo el período: alimentos y leña (comprobantes de compras y otros gastos de la Cárcel Penitenciaría y los Hospitales Emilio Civit y San Antonio ${ }^{18}$ ) y vivienda y vestimenta (presupuestos provinciales).

Tabla 2. Índice de Costo de Vida para Mendoza, 1895-1914

\begin{tabular}{ccccc}
\hline \multirow{2}{*}{ Año } & Índice de Costo de Vida & & Índice de Costo de Vida \\
\cline { 2 - 2 } & Base $1895=100$ & & Base $1895=100$ \\
\hline 1895 & 100 & & 93 \\
1896 & 103 & 1905 & 100 \\
1897 & 100 & 1907 & 126 \\
1898 & 101 & 1908 & 149 \\
1899 & 97 & 1909 & 164 \\
1900 & 88 & 1910 & 185 \\
1901 & 86 & 1911 & 191 \\
1902 & 88 & 1912 & 185 \\
1903 & 90 & 1913 & 224 \\
1904 & 90 & 1914 & 235 \\
\hline
\end{tabular}

Fuente: Elaboración propia en base a Prieto y Chorén (1990), Coria (2004), Registros Oficiales de la Provincia de Mendoza y Leyes de Presupuesto para el período 1895-1914.

Nota: Para los años en que el precio de algunos artículos no estaba disponible en el repositorio consultado, el valor correspondiente fue calculado en función de su tendencia histórica. Así, fue posible construir la

\footnotetext{
${ }^{17} \mathrm{Si}$ bien las autoras adicionan otros bienes (papas, zapallo, huevos, vino y trigo pelado), como los mismos no están disponibles en las fuentes consultadas para 1895-1914 se ha supuesto que se comportaron de manera similar a los disponibles. Además, la ponderación resultante se considera adecuada teniendo en cuenta que, en este trabajo, interesa una canasta para cuatro personas y no para seis. Si bien este supuesto implica que las preferencias del consumidor se mantuvieron estables en todo el período, el mismo resulta consistente con la canasta construida por Richard Jorba $(2012 ; 450)$ para un una familia de trabajadores no calificados compuesta por un matrimonio y dos hijos para 1910-1911, ya los siete artículos representan el $71 \%$ del consumo de alimentos y leña. La ponderación asignada al alquiler es similar a las consideradas por Alejandro Bunge (20\%) y por Cortés Conde (1979) (22\%); la que corresponde a vestimenta, se ha calculado por diferencia $(18,7 \%)$, y es un poco más elevada que las consideradas por Bunge $(15 \%)$ y Cortés Conde (13\%).

${ }^{18}$ Los precios de los alimentos y de la leña fueron relevados en el Archivo provincial por un equipo de investigación dirigido por Luis Coria; una síntesis de los resultados se publicó en Coria (2004).
} 
serie completa del índice para cada bien, para luego calcular el índice ponderado de los seis alimentos y la leña, y sumar los correspondientes a alquiler y vestimenta.

El Índice de Costo de Vida calculado a partir de ella muestran un fuerte descenso de precios en el intervalo 1899-1905, una recuperación en 1906 y, un posterior y significativo ascenso hasta 1914; los valores para este último año más que duplican a los correspondientes a 1895. En efecto, la mejora económica que se registró luego de la salida de la crisis vitivinícola y desde 1905, la expansión monetaria nacional y provincial, efectivizada a través de la emisión de letras de tesorería (Coria, 2004), habrían contribuido al incremento de los precios locales. Algunos mercados de bienes y servicios, además, atravesaron por situaciones particulares que derivaron en una menor oferta y en el consiguiente aumento de sus precios. Así ocurrió con la carne vacuna, cuando la reducción del stock de ganado en pie obligó a importarla de otras provincias ${ }^{19}$ con el consiguiente aumento de los fletes, y, sobre todo, con el mercado inmobiliario. El precio del alquiler de un cuarto en la Ciudad, que se había mantenido estable desde el inicio del período, comenzó una escalada hacia mediados de la década de 1900: desde un valor de m\$n 12 en 1907 llegó a m\$n 60 en 1914. Este incremento refleja el crecimiento poblacional y, en particular, la llegada masiva de inmigrantes ${ }^{20}$, cuya tendencia alcista arranca en 1896 y se detiene, como se sabe, por la guerra y la crisis (el Censo Nacional de Población de 1914 señala que la población oriunda de Europa alcanzó el 32\% del total provincial). De hecho, desde 1908 la prensa local refiere frecuentemente la escasez de viviendas disponibles en la Ciudad y departamentos aledaños; asimismo, proporciona información sobre el remate de zonas urbanizables y la venta de fracciones de lotes. El aumento del precio de la vivienda urbana, según Bértola Flores (2005), fue común a las sociedades de nuevo asentamiento (Argentina, Uruguay, Australia y Nueva Zelanda), a pesar de ser abundantes en tierra, ya que el aluvión inmigratorio congestionó las ciudades y la vivienda se transformó en un recurso muy escaso. Por otra parte, las preferencias residenciales de los inmigrantes modificaron la composición social de las áreas urbanas, y de los departamentos rurales del este y el sur provincial. Entre 1895 y 1914, la población urbana aumentó un $352 \%$ y la rural un $64 \%$. Los inmigrantes, y sus familias, pasaron a integrar contingentes móviles de trabajadores urbanos: las obras destinadas a reconstruir la ciudad luego del terremoto de 1861, el tendido de ramales

\footnotetext{
${ }^{19}$ Este problema se agravaría años más tarde. Los gobiernos de orientación radical "populista” (1918-1928) propusieron diversificar la economía revitalizando la ganadería, y con ella los cultivos de alfalfa, a fin de abastecer de carnes el mercado local y proveer de hacienda en pie y carne a toda la costa del Pacífico gracias al Ferrocarril Trasandino, que había unido Mendoza y Chile en 1910. Además, sería entonces necesario construir mataderos y frigoríficos, que también podrían ser utilizados para conservar frutas y legumbres que se exportarían a otras provincias. No obstante, la fuerte recuperación que experimentó el mercado vitivinícola durante los años veinte postergó en gran parte estas iniciativas (Olguín, 2015).

${ }^{20}$ Véase en particular, Devoto (2002) y Cozzani de Palmada (1997). Según información proveniente de la Oficina Nacional del Trabajo, Mendoza era el cuarto destino elegido por los inmigrantes internados en Argentina: de un total de 40.489 personas, ingresaron 4.063, luego de Buenos Aires (10.848), Santa Fe (9.371), Córdoba (5.117); detrás de la Provincia seguían Tucumán (2.488), Entre Ríos (1.205) y otras provincias.
} 
y estaciones ferroviarias, la construcción de canales, diques, puentes, entre otras obras públicas y privadas, se convirtieron en emporios laborales al tiempo que la creciente expansión del comercio y la proliferación de bodegas, talleres y fábricas de conservas reclutaron mano de obra femenina e infantil. ${ }^{21}$ De modo que el costo de la vivienda, que no fue considerado en los estudios sobre Buenos Aires entre fines de la Colonia y mediados del siglo XIX debido a la escasez de fuentes (Allen, 2001; Arroyo Abad, Davies y van Zanden, 2011; Gelman y Santilli, 2016), y cuya omisión probablemente no modifique sustancialmente los resultados, se convirtió en una variable clave entre 1895 y 1914. En efecto, el índice de precios de alimentos que Correa Deza y Nicolini (2014) calcularon para Mendoza arroja descensos para 1908, 1909 y 1910, al no incluir el precio de los alquileres (aunque la heterogeneidad de fuentes y metodologías no permita hacer comparaciones con esta investigación en sentido estricto).

\section{Salarios reales de trabajadores de baja y mediana calificación}

Habría que examinar el impacto del movimiento de precios en el poder adquisitivo de los salarios de empleados públicos y trabajadores del sector privado. Al respecto, vale tener en cuenta que no fueron pocas las voces de época que enfatizaron las oportunidades de empleo que ofrecía la joven industria a nativos y extranjeros. Valga como ejemplo el informe oficial de 1888 que fuera preparado para la Exposición de París por Abraham Lemos, quien anotaba que la provincia adolecía de brazos suficientes para avanzar en el sendero del progreso por lo que no dejó de subrayar los altos salarios como estímulo para atraer inmigrantes europeos. ${ }^{22}$ Años después, más precisamente en 1904, Juan Bialet Massé hacía notar las "condiciones obreras extraordinarias” que había ofrecido la provincia a raíz del arribo del ferrocarril, el ingreso masivo de inmigrantes y el desarrollo vitivinícola promovido por sus dirigencias, el cual le hizo consignar que "Mendoza ha progresado mucho en el orden de la riqueza" aunque tenía aún pendiente instalar la "cuestión social" en la agenda pública a los efectos de moralizar las clases trabajadoras, y equiparar las chances y habilidades de la mano de obra criolla y la extranjera. ${ }^{23}$ Dicho señalamiento resultó acompañado de otras observaciones interesantes sobre las características del mercado de trabajo rural y urbano: Bialet Masé consignó la importancia del componente familiar del régimen de contratistas de viña ${ }^{24}$,

${ }^{21}$ Si bien los especialistas han subrayado los límites de las categorías censales como instrumentos fieles de las ocupaciones (y eventual movilidad) del mercado de trabajo, la sostenida atracción de mano de obra europea y el variopinto cuadro socio-ocupacional que arrojan los datos censales resultan de interés para señalar su alcance y consignar algunas notas sobre su distribución territorial y ocupacional.

${ }^{22}$ Mendoza. Memoria Descriptiva de la Provincia. Obra mandada a ejecutar por el Exmo. Gobierno de la Provincia para concurrir a la Exposición de París. Mendoza, Tipografía Los Andes, 1888, pp. 63-66.

${ }^{23}$ Bialet Massé, J. 1986. Informe sobre el estado de la clase obrera en el Interior de la República. T. II. Buenos Aires: Hyspamérica, pp. 859-877. Las condiciones de trabajo, y en particular la figura del contratista, fueron estudiadas por Salvatore (1986) en un artículo pionero en el cual postuló hipótesis sugerentes sobre las formas de explotación agrarias que gravitaron en favor de los propietarios de viñas.

${ }^{24}$ El "contratista de plantación" pactaba con el propietario hacerse cargo de implantar viñedos mediante la reconversión productiva, incorporación de terrenos incultos o ambos. En la mayoría de los casos, percibía al término del período fijado una suma de dinero por cada cepa implantada y se apropiaba del fruto de una 
señaló la diferencia entre trabajo estable y el carácter estacional de la mano de obra, consignó que los salarios de las mujeres solían ser más altos al de otras provincias visitadas, y subrayó el rol del ahorro doméstico en el paso de peón o trabajador rural y/o urbano, a patrón y/o propietario.

Sin embargo, las estadísticas oficiales no permiten constatar el valor monetario de los salarios ni menos aún su poder adquisitivo. Dicha limitación requirió la construcción de series continuas de salarios nominales y reales de los sectores público y privado. La selección de las categorías consignadas de empleados públicos (peón de policía, portero y escribiente) obedeció a la idea de cotejar la tendencia general de los salarios estatales entre personal con diferentes calificaciones laborales (baja, para los dos primeros, y mediana, para el tercero). A su vez, la serie más discreta de salarios percibidos por los peones de los establecimientos Arizu (correspondiente al año 1895, 1898 y a los años comprendidos entre 1908 y 1914) busca verificar la evolución de la remuneración de trabajadores del sector industrial más dinámico. Estas series, junto con las del costo de una canasta de subsistencia y el Índice de Costo de Vida, especificados más arriba, se presentan a continuación.

Tabla 3. Salarios nominales y reales de trabajadores y costo de una canasta de subsistencia, 1895-1914

\begin{tabular}{|c|c|c|c|c|c|c|c|c|c|}
\hline \multirow{3}{*}{ Año } & \multicolumn{4}{|c|}{ Salarios nominales } & \multirow[b]{2}{*}{$\begin{array}{l}\text { Costo } \\
\text { de la } \\
\text { canasta }\end{array}$} & \multicolumn{4}{|c|}{ Salarios reales } \\
\hline & Policía & Portero & $\begin{array}{l}\text { Escri- } \\
\text { biente }\end{array}$ & $\begin{array}{c}\text { Peón } \\
\text { Bodega } \\
\text { Arizu }\end{array}$ & & Policía & Portero & $\begin{array}{l}\text { Escri- } \\
\text { biente }\end{array}$ & $\begin{array}{c}\text { Peón } \\
\text { Bodega } \\
\text { Arizu }\end{array}$ \\
\hline & \multicolumn{5}{|c|}{$\mathrm{m} \$ \mathrm{n}$ por mes } & \multicolumn{4}{|c|}{$\mathrm{m} \$ \mathrm{n}$ de 1895 por mes } \\
\hline 1895 & 35 & 30 & 55 & 35,0 & 62,6 & 35 & 30 & 55 & 35 \\
\hline 1896 & 40 & 30 & 55 & $\mathrm{~s} / \mathrm{d}$ & 64,9 & 39 & 29 & 53 & - \\
\hline 1897 & 40 & 30 & 60 & $\mathrm{~s} / \mathrm{d}$ & 64,7 & 40 & 30 & 60 & - \\
\hline 1898 & 40 & 30 & 60 & 40,0 & 65,9 & 40 & 30 & 59 & 40 \\
\hline 1899 & 40 & 30 & 60 & $\mathrm{~s} / \mathrm{d}$ & 62,2 & 41 & 31 & 62 & - \\
\hline 1900 & 40 & 30 & 60 & $\mathrm{~s} / \mathrm{d}$ & 55,4 & 45 & 34 & 68 & - \\
\hline 1901 & 40 & 30 & 70 & $\mathrm{~s} / \mathrm{d}$ & 55,2 & 46 & 35 & 81 & - \\
\hline 1902 & 40 & 30 & 70 & $\mathrm{~s} / \mathrm{d}$ & 55,6 & 45 & 34 & 79 & - \\
\hline 1903 & 40 & 30 & 70 & $\mathrm{~s} / \mathrm{d}$ & 56,0 & 45 & 33 & 78 & - \\
\hline 1904 & 38 & 29 & 67 & $\mathrm{~s} / \mathrm{d}$ & 55,4 & 42 & 32 & 75 & - \\
\hline 1905 & 40 & 35 & 90 & $\mathrm{~s} / \mathrm{d}$ & 55,2 & 43 & 38 & 97 & - \\
\hline 1906 & 50 & 40 & 90 & $\mathrm{~s} / \mathrm{d}$ & 59,4 & 50 & 40 & 90 & - \\
\hline 1907 & 60 & 60 & 100 & $\mathrm{~s} / \mathrm{d}$ & 71,4 & 48 & 48 & 80 & - \\
\hline 1908 & 75 & 70 & 100 & 55,0 & 83,0 & 50 & 47 & 67 & 37 \\
\hline 1909 & 75 & 80 & 100 & 50,0 & 89,6 & 46 & 49 & 61 & 30 \\
\hline 1910 & 75 & 80 & 100 & 50,0 & 100,5 & 41 & 43 & 54 & 27 \\
\hline 1911 & 75 & 80 & 100 & 51,3 & 104,9 & 39 & 42 & 52 & 27 \\
\hline 1912 & 85 & 80 & 120 & 52,5 & 101,8 & 46 & 43 & 65 & 28 \\
\hline 1913 & 90 & 80 & 120 & 55,0 & 123,5 & 40 & 36 & 54 & 25 \\
\hline 1914 & 90 & 100 & 120 & 52,5 & 131,1 & 38 & 43 & 51 & 22 \\
\hline
\end{tabular}

Fuente: Elaboración propia en base a Registros Oficiales de la Provincia de Mendoza y Leyes de Presupuesto para el período 1895-1914, Archivo General de la Provincia de Mendoza, Libros de jornales de Bodegas Arizu 1898, 1908-1914, Coria (2004) y Tabla 2.

Nota: El valor del jornal del peón para 1895 ha sido estimado en base a fuentes de época. Según documentos

o varias cosechas. Esta figura desapareció en la década de 1930, quedando en su lugar el "contratista de mantenimiento" que no necesitaba contar con un capital propio (Richard Jorba, 2003; 21-23). 
empresariales de Bodegas Arizu, en 1890 era de $\mathrm{m} \$ \mathrm{n}$ 1,10/1,50 por día, es decir que para un mes de 25 días de trabajo variaba entre m\$n 27,5/37,5. Asimismo, en 1893, según la Dirección General de Inmigraciones, un agricultor ganaba entre 20 y 40 pesos por mes pero con familia el sueldo era mayor: entre 30 y 70 (Prieto y Chorén, 1991-1992; 133). En el mismo año, los jornales mensuales variaron entre m\$n 30 y 80 (Richard Jorba, 2012; 452). Por otra parte, el jornal para el período 1908-1914 (corresponden a la Finca Chachingo, situada en Maipú) ha sido calculado en base al valor medio entre el mínimo y el máximo para los meses de febrero-marzo (temporada alta) y junio-julio (temporada baja). El valor final resulta del promedio de ambos subperíodos a fin de considerar la estacionalidad. Los jornales diarios han sido mensualizados considerando 25 días de trabajo al mes, como sugiere la bibliografía especializada.

De acuerdo a la tabla anterior, los salarios nominales para las tres categorías de empleados públicos se mantuvieron estables hasta 1904, año en que la política fiscal de austeridad implementada por el gobierno provincial para superar la crisis de 1900-1903 incluyó la reducción de las remuneraciones del personal estatal. Entre 1905 y 1908 se registró un importante aumento. Dicha evolución favorable resulta correlativa con la expansión del gasto público que se aceleró a partir de 1905 (aun considerando las etapas inflacionarias), cuando la creciente producción de vinos se consolidó como fuente de recursos fiscales al proporcionar alrededor del 50\% de la recaudación. Asimismo, el aumento de los salarios de los peones de policía coincidió con la mayor inversión pública de la administración provincial en manos del gobernador Emilio Civit, el líder del roquismo en Mendoza. Hacia el final del período, en coincidencia con la etapa de consolidación de la vitivinicultura, los salarios permanecieron invariables, excepto por algunos aumentos específicos otorgados a policías y escribientes en 1912 y a porteros en 1909 y 1914.

Sin embargo, los salarios nominales subieron poco más que el Índice de Costo de Vida en el lapso de veinte años, es decir, en términos reales mejoraron levemente, $\mathrm{y}$, en algunos casos, empeoraron: la remuneración real del peón de policía (en $\mathrm{m} \$ \mathrm{n}$ de 1895) pasó de 35 en 1895 a 38 en 1914; la del portero de 30 a 43, respectivamente, y la del más calificado de los tres, de 55 a sólo 51, en cada uno de esos años. De hecho, las tasas de crecimiento anual acumulado sólo alcanzaron al 15\%, al 43\% y al 8\%, en cada caso. La tendencia general indica un amplio margen de variabilidad en las tasa de crecimiento anual como consecuencia de las modificaciones de los niveles del Índice de Costo de Vida: frente a la relativa estabilidad que prevalece en los salarios nominales entre 1895 y 1903, las caídas en el nivel de precios influenciadas por la estabilidad monetaria y cambiaria que siguió a la crisis de 1890 y por la crisis vitivinícola de 1900-1903, impactaron favorablemente en los salarios reales. Pero las mejoras en las remuneraciones nominales concedidas a partir de 1905 fueron más que compensadas por el progresivo ascenso en el nivel de precios desde 1906 (aunque no para las tres categorías), y a excepción de 1912, siendo los escribientes los más perjudicados; como se apuntó más arriba, la escalada en el costo de vida estuvo fuertemente influida por el aumento del precio de la carne y, sobre todo, el de los alquileres. En efecto, las tasas de crecimiento anual registran sus mayores valores, en el caso de los policías, en 1896 (11\%), 1900 (10\%), $1906(16 \%)$ y $1912(17 \%)$; en el de los porteros, en $1900(10 \%)$, 1905 (17\%), 1907 (20\%) y 1914 (19\%); y en el de los escribientes, en $1897(12 \%)$, 1900 (10\%), 1901 (19\%), $1905(30 \%)$ y 1912 (24\%). Considerando tasas promedio 
por quinquenios, se advierten los períodos en que los salarios aumentaron más, que corresponden a leves incrementos: para los primeros, un 4\% en el intervalo 1895-1899; para los segundos, un 9\% en 1905-1909, y, para los terceros, un 4\% en 1900-1904.

Por otra parte, en las series más cortas de salarios nominales de los peones de viña de la Bodega Arizu se destaca un descenso (en m\$n de 1895) de 55 en 1908 a 50 en 1909, y una leve recuperación posterior que terminó por alcanzar el nivel inicial en 1913, para volver a caer el año siguiente a 53, probablemente por los efectos de la crisis de 1914 que instaló una profunda depresión en la economía y cuyos efectos comenzaron a notarse dos años antes. Estas evidencias en torno a la caída de las remuneraciones resultan llamativas porque se produjeron en pleno período de expansión de la vitivinicultura. Podrían deberse a una relativa abundancia de mano de obra de baja calificación aportada por la inmigración (Williamson, 2002), así como a la mayor flexibilidad a la baja de los salarios privados vinculadas a actividades económicas de base de agrícola en relación con las de los empleados de la administración pública, que son rígidos a la baja (únicamente sufrieron una caída en 1904, que en las categorías seleccionadas osciló entre el 3\% y el 5\%); de manera que en momentos de menor necesidad de mano de obra o de dificultades financieras, las empresas estaban en mejores condiciones para reducir los sueldos o el número de personal contratado.

Al expresar los valores nominales en precios de 1895 se aprecia una estrepitosa caída aunque con algunos altibajos, ya que en esos años se produjo un fuerte ascenso del Índice de Costo de Vida: de 37 en 1908, los salarios reales se derrumbaron a 22 en 1914, con lo cual perdieron el $40 \%$ de su valor. Las tasas de crecimiento anual acumuladas cayeron el 46\%, y sólo en 1912 registraron una variación positiva (6\%). En el intervalo 1909-1914, la tasa promedio de crecimiento anual exhibe un descenso del 8\%.

Un modo de ponderar el poder adquisitivo de los salarios es cotejarlos con el costo de la canasta de subsistencia. Cabe señalar que las participaciones relativas de los bienes en el costo total se modificaron durante el período por efecto de los cambios en los precios: la carne de vaca aumentó de $22 \%$ en 1895 a $25 \%$ en 1914 , el pan que había aumentado de $17 \%$ en 1895 a 20\% en 1905 descendió a 11\% en 1914, y el costo del alquiler fue sin duda el que ganó mayor peso relativo al subir del $15 \%$ en 1895 al $46 \%$ en 1914. Sin embargo, conviene advertir que el costo de vida en las zonas rurales era más bajo que en la ciudad, de modo que el salario real del peón de viña fue probablemente mayor al calculado. Hemos detectado que el costo del alquiler de casas para comisarías podía ser un 50\% más bajo en Maipú que en el Departamento Capital; otro tanto ocurría con los alimentos, ya que algunos se producían de modo doméstico o se obtenían en la misma finca.

Es importante notar que sólo el escribiente estuvo en condiciones de adquirirla en el período 1900-1909, aunque el peón de policía y el portero exhibieron una mayor estabilidad en su capacidad de compra, lo cual les permitió soportar mejor la crisis iniciada en 1914. De modo que el resto de las categorías consideradas debían engrosar el ingreso familiar con fondos provenientes de otros miembros y/u otras actividades. En particular, es importante tener en cuenta que el salario del peón rural 
probablemente no constituía el único ingreso familiar, ya que era común el trabajo de mujeres y niños en las fincas y bodegas, así como en fábricas de conservas. El Censo Nacional de Población de 1895 consignó que los hijos, parientes o arrimados al jefe del hogar en general trabajaban (81\%) como jornaleros (59\%), prestando servicios personales $(35 \%)$ y como agricultores $(6 \%)$; por su parte, el cónyuge que trabajaba (33\%) prestaba servicios personales, frecuentemente vinculados a las tareas domésticas (Prieto y Chorén, 1991-1992; 136 y 137). Asimismo, algunas experiencias exitosas de trabajadores devenidos en empresarios también han destacado las estrategias de diversificación de actividades (comercio, préstamo de dinero, etc.) como una forma de disponer de fuentes alternativas de ingresos. Igualmente, es necesario recalcar que las condiciones y retribuciones laborales diferían entre empresas de distinto tamaño y localización geográfica. No obstante, de acuerdo a información oficial sobre los salarios cobrados por quienes desempeñaban distintos oficios u ocupaciones en 1910, probablemente de forma independiente, el pago recibido por el peón de Bodegas Arizu ( $m \$ n 2$ por día) fue similar al del jornalero (entre $m \$ n 2$ y $m \$ n 3)$, cuyos ingresos eran los más bajos de las categorías consideradas ${ }^{25}$.

La comparación entre las trayectorias de los salarios reales públicos y de los arroja interesantes resultados, como se ilustra en el Gráfico 2.

Gráfico 2. Salarios reales de trabajadores públicos y privados, 1895-1914

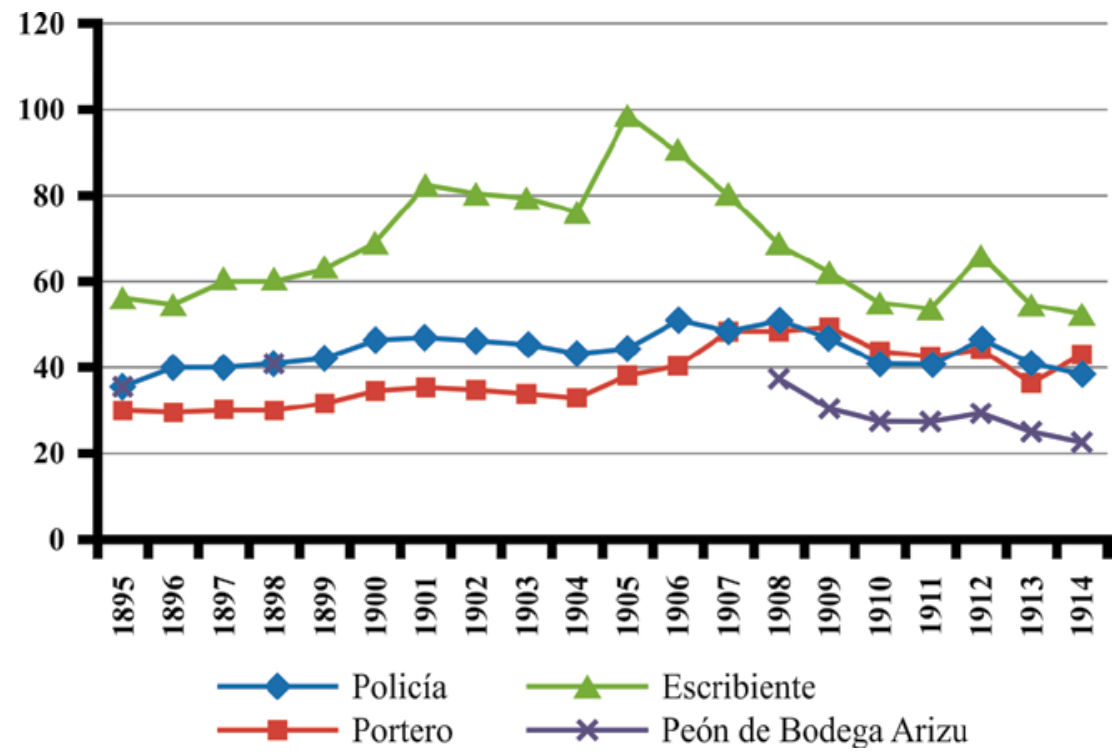

Fuente: Elaboración propia en base a Tabla 3

\footnotetext{
${ }^{25}$ Los salarios de los empleados de finca de Bodegas y Viñedos Giol para 1912 muestran en promedio remuneraciones más altas (entre $\mathrm{m} \$ \mathrm{n} 4,8$ y $\mathrm{m} \$ \mathrm{n}$ 9,2 para un mes de 25 días trabajados). Lo mismo ocurrió con otras ocupaciones, cuya retribución superaba al promedio provincial y al salario de los empleados públicos que se desempeñaban en el mismo puesto (como el caso el portero). En el caso de la firma Giol, esta situación puede haberse debido a una política empresarial o a los lazos de paisanaje existentes entre Juan Giol y algunos trabajadores que procedían de su lugar de origen, Vigonovo di Fontanafredda, ubicado en el norte del Italia (algunos eran de apellido Giol).
} 
El comportamiento de las variables muestra, por un lado, que los mayores ingresos generados por la vitivinicultura fueron recibidos en mayor proporción por los empleados públicos (a través de la asignación de la recaudación del impuesto al vino al pago de salarios) que por los trabajadores de las viñas, cuyos ingresos nominales tuvieron un crecimiento muy inferior e, incluso, marcados descensos. Estas evidencias complejizan el argumento sostenido por bibliografía especializada en relación con que los salarios no aumentaron en todo el período, ya que el salario real creció en 1898 y 1908 si se lo compara con su valor para 1895, aunque se expandió mucho menos que los salarios públicos más bajos de la administración provincial (esta diferencia sería menor si se considerara un incremento inferior de los precios en las zonas rurales). En efecto, a partir de 1909 el salario real del peón inició una caída sostenida que sólo se compara con la que registró el escribiente: en 1914, estos fondos representaban, en el caso del peón, el 64\% del que obtuvo en 1895 y, en el del escribiente, el 93\%. Por su parte, las remuneraciones del peón de policía y el portero también disminuyeron (desde 1909 para el primero y desde 1910 para el segundo) por el alza en el costo de vida pero no adoptaron valores inferiores a los de 1895. De hecho, en la etapa 1909-1914 los salarios fueron mayores que los de 1895 aunque notablemente más bajos que los máximos alcanzados en 1906 y 1908 en el caso del policía (m\$n 50) y 1909 en el del portero $(\mathrm{m} \$ \mathrm{n} 49)$.

Resulta ilustrativo cotejar los salarios de los peones de policía y los índices de precios calculados para Mendoza con los disponibles para Buenos Aires para el período 1895-1912 (Cortés Conde, 1979). ${ }^{26}$ Los salarios nominales fueron inferiores en Mendoza hasta 1907, en que igualaron a las de Buenos Aires para superarlas hasta 1912. Sin embargo, los salarios reales estuvieron muy por debajo de los de esta provincia entre 1898 y 1907 aunque se expandieron de manera más estable y sostenida. La brecha se cerró recién al final del período cuando el fuerte aumento de los salarios nominales permitió aumentar el poder adquisitivo de los trabajadores mendocinos a pesar del alza de precios que se registró desde 1905. Las tasas de crecimiento para Mendoza muestran valores más elevados (o menores descensos) en 1896, 1900-1902, 1906 y 1908-1909, mientras que en 1911 y 1912 tuvieron un comportamiento similar al de Buenos Aires. En síntesis, los salarios del peón de policía en Mendoza cubrieron peor sus gastos de alimentación que sus pares de la capital, en particular entre 1898 y 1907. La contribución de Cuesta (2012) muestra algunas diferencias en la estimación del salario real del peón de policía (además del correspondiente al enfermero, portero y maestranza) para esa provincia del litoral. Sobre la base de un Índice de Costo de Vida, estima un gran aumento en los salarios reales para el período 1880-1914, aun durante la crisis financiera de 1890, lo cual es atribuido por el autor a la consolidación de las instituciones políticas argentinas. Algunas de las claves para comprender las diferencias interprovinciales en los precios de los bienes de consumo popular fueron aportadas por Correa Deza y Nicolini (2014). La evidencia obtenida permitió diferenciar provincias más caras (San Juan, Mendoza, Jujuy, Posadas) de otras más baratas (Buenos Aires, Córdoba, Rosario, Santa Fe); esta

\footnotetext{
${ }^{26}$ Los índices de salarios y del precio de alimentos y leña han sido reexpresados en base $1903=100$ para
} hacer posible la comparación. 
distinción habría estado vinculada a la especialización productiva de las provincias del litoral en la producción de carne y pan, el costo del flete y el tamaño de los mercados consumidores.

Por último, resulta interesante analizar la evolución del cociente salarios nominales/recursos propios (variable proxy del $\mathrm{PBI}$ ) para cada categoría de trabajador, como se dibuja en el Gráfico 3.

Gráfico 3. Salarios nominales en relación con los recursos de origen propio, 1895-1914

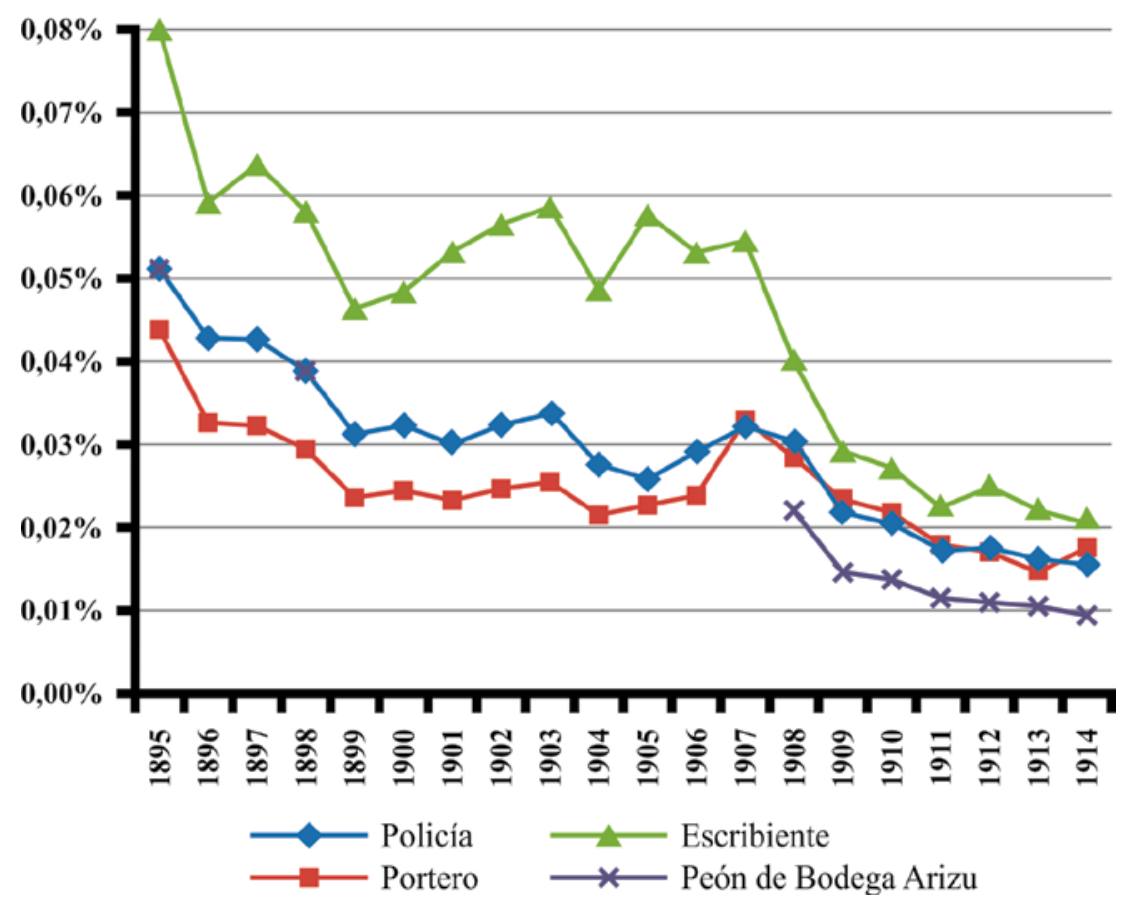

Fuente: Elaboración propia en base a Anuario Estadístico de Mendoza para 1914 y Tabla 3

Los salarios muestran una tendencia decreciente en todos los casos, es decir que a medida que se aceleró el ritmo del crecimiento económico de Mendoza, estas categorías de empleados públicos y el peón de Bodegas Arizu participaron cada vez menos de sus beneficios (en término del valor de las remuneraciones percibidas). La mayor caída en el ratio calculado corresponde al escribiente, que desde 1908 redujo la brecha que lo distanciaba del resto.

\section{Principales resultados}

Este trabajo ofrece resultados novedosos sobre los efectos de la transformación vitivinícola que tuvo lugar entre fines del siglo XIX y 1914. A partir de la consulta de diversas fuentes (como los presupuestos provinciales, anuarios estadísticos y 
documentos empresariales), así como de estudios pioneros sobre condiciones de vida y precios mayoristas en Mendoza, se construyeron series continuas de salarios reales para empleados públicos de baja y mediana calificación y el peón de viña de Bodegas Arizu. La evidencia empírica construida, siguiendo metodologías y procedimientos validados por el campo del conocimiento, pretende enriquecer el debate en torno a un tema que ha recobrado notoriedad en la historiografía: los cambios en la desigualdad social en el largo plazo.

La trayectoria de los salarios nominales de los empleados públicos fue tributaria del crecimiento económico provincial (aunque se expandieron a un menor ritmo), que engrosó la recaudación fiscal gracias a los gravámenes establecidos al vino de mesa. Estos valores subieron poco más que el Índice de Costo de Vida en el lapso de veinte años, es decir, en términos reales no mejoraron sustancialmente al ser más que compensados por la escalada en los precios locales que precedió a la crisis de 1914 (en particular, del alquiler y de la carne vacuna), y, en el caso del escribiente, empeoraron. Por otra parte, las series más cortas de salarios nominales del peón de viña muestran un incremento muy inferior al de aquéllos; expresado en valores constantes, sufrieron marcados descensos hacia el final del período, aunque, oportunamente, se advirtió sobre el menor costo de vida en las zonas rurales. Asimismo, es importante notar que sólo el escribiente estuvo en condiciones de adquirir la canasta de subsistencia en el intervalo 1900-1909; de modo que las remuneraciones del sector público, y del sector vitivinícola, fueron insuficientes para solventar el costo de vida de sus familias.

Estas evidencias invitan a revisar el argumento sostenido por bibliografía especializada en relación con que los salarios nominales de peones y jornaleros no aumentaron en todo el período (ya que éste no sólo creció sino que el salario real se elevó en 1898 y 1908, si se lo compara con su valor para 1895, y probablemente el alza fue mayor a la estimada). Por otra parte, proponen nuevos ejercicios de reflexión a partir de los contrastes advertidos en relación con los estudios disponibles para otras provincias del país, en particular para la ciudad de Buenos Aires. Conviene reiterar la prevención de que los resultados no son estrictamente comparables, teniendo en cuenta las diferencias relativas a las fuentes y metodologías de investigación ${ }^{27}$. De la confrontación de estos últimos con las estimaciones de Cortés Conde (1979) y Cuesta (2012) surge que los salarios reales del peón de policía en Mendoza tuvieron un menor crecimiento. Esta situación podría estar vinculada a las características propias de la estructura económica (de base agroindustrial), y a su articulación con el mercado nacional. En este sentido, Correa Deza y Nicolini (2014) informaron para Mendoza mayores precios relativos de la carne y el pan, un elevado costo de transporte y un tamaño relativamente reducido del mercado doméstico; si hubieran incluido el costo de la vivienda, probablemente,

\footnotetext{
${ }^{27}$ En relación con la contribución de Cuesta (2012), en ambos casos las canastas de bienes y servicios fueron elaboradas en base a observadores de época no neutrales (Informe de la Dirección Provincial de Inmigraciones, 1893, para Mendoza, e datos proporcionados por Alfredo Palacios, 1892, para Buenos Aires). Sin embargo, en el de Mendoza las fuentes sobre precios resultan más confiables (recopilados de las facturas de compra de los mismos proveedores en el caso de los alimentos y leña, y de los presupuesto provinciales, en el caso de vivienda y vestimenta).
} 
habrían encontrado otro elemento diferenciador. En efecto, un corolario de los ejercicios cuantitativos realizados es la necesidad de incluir el precio del alquiler en el cálculo del Índice de Precios para el período 1895-1914, y no sólo el de los alimentos.

Finalmente, y más allá de los matices expuestos, resulta esclarecedor apreciar el desempeño el sector público en el crecimiento económico provincial y en la capacidad adquisitiva del salario; un aspecto que sin duda debe ser profundizado, y cotejado con el desempeño del salario industrial o de la construcción. Dicho aspecto resulta relevante a los fines que esta investigación persigue, sobre todo al contrastar el aumento exponencial de las recursos públicos (el presupuesto provincial en pesos oro se multiplicó 12 veces en el período), y la decreciente proporción de las categorías más bajas de la administración pública provincial (peón de policía), que pasó del 19\% del presupuesto en 1895 (400 vigilantes), al 4,5\% en 1914 (300 vigilantes).

\section{Referencias bibliográficas}

Allen, R. C. 2001. "The Great Divergence in European Wages and Prices from the Middle Ages to the First World War". Explorations in Economic History, 4 (Vol. 38), Elsevier.

Arroyo Abad, L. 2013. "Inestabilidad, costo de vida y salarios reales en Venezuela en el siglo XIX". América Latina en la Historia Económica, 3, Año 20.

Arroyo Abad, L., Davies, E. and van Zanden, J. L. 2011. "Between conquest and independence: Real wages and demographic change in Spanish America, 15301820". CGEH Working Papers, 20.

Balán, J. 1978. "Una cuestión regional en la Argentina: burguesías provinciales y el mercado nacional en el desarrollo agroexportador". Desarrollo Económico, 69, IDES.

Balán, J. y López, N. 1977. "Burguesías y gobiernos provinciales en la Argentina. La política impositiva de Tucumán y Mendoza entre 1873 y 1914”. Desarrollo Económico, 67, IDES.

Barrio de Villanueva, P. 2002. Una crisis de la vitivinicultura mendocina a principios del siglo XX (1901-1903). En XVIII Jornadas de Historia Económica, Universidad Nacional de Cuyo, Mendoza.

Bértola, L, Camou, M, and Porcile, G. 1999. Comparación internacional del poder adquisitivo de los salarios reales de los países del Cono Sur, 1870-1945. En: Segundas Jornadas de Historia Económica, Montevideo.

Bértola Flores, L. 2005. "A 50 años de la curva de Kuznets: crecimiento económico y distribución del ingreso en Uruguay y otras economías de nuevo asentamiento desde 1870". Investigaciones de Historia Económica, 3.

Bragoni, B. 1999. 'Meritorios españoles, ejemplares nobles'. Inmigración, redes y mercado: notas sobre la formación de emporios vitivinícolas en Mendoza, 18601940". En A. Fernández, A. y J. Moya (Ed.), La inmigración española en la Argentina. Buenos Aires: Biblos. 
Campi, D. 2004. "La evolución del salario real del peón azucarero en Tucumán (Argentina) en un contexto de coacción y salario 'arcaico' (1881-1893)". América Latina en la Historia Económica, 22, 105-128.

Coria, L. A. 2004. Los precios en Mendoza en dos décadas: 1895-1914. En Jornadas de Ciencias Económicas, FCE-UNCuyo, Mendoza.

Coria, L. A. 2006. "El siglo anterior al boom vitivinícola mendocino (1780-1883)". Revista Universum, 21, Vol. 2.

Coria, L. A. 2010. "El boom vitivinícola de Mendoza (Argentina) y su impacto espacial interno (1883-1914)". Estudios Avanzados, 14.

Correa Deza, M. F. y Campi, D. 2009. La evolución del salario real del peón azucarero tucumano, 1881-1927. En VIII Congresso Brasileiro de História Econômica e $9^{a}$ Conferência Internacional de História de Empresas. Associação Brasileira de Pesquisadores em História Econômica (ABPHE), Campinas, São Paulo.

Correa Deza, M. F. y Nicolini, E. A. 2014. "Diferencias regionales en el costo de vida en Argentina a comienzos del siglo XX”. En Investigaciones de Historia Económica, 10, 202-212.

Cortés Conde, R. 1979. El progreso argentino, 1880-1914. Buenos Aires: Sudamericana. Cozzani de Palmada, M. R. 1997. Sociedades y espacios de migración: Los italianos en la Argentina y en Mendoza. Mendoza: EDIUNC.

Cuesta, M. 2012. "Precios y salarios en Buenos Aires durante la Gran Expansión (1850-1914)". Revista de Instituciones, Ideas y Mercados, Instituto Universitario ESEADE, Vol. 56.

Devoto, F. 2002. Historia de la inmigración en la Argentina. Buenos Aires: Sudamericana. Djenderedjian, J. \& Martiren, J. L. 2015. "Precios, producto agrario y niveles de vida en las fronteras rioplatenses, 1700-1810: una nueva mirada sobre el crecimiento económico tardocolonial". Revista de Historia Económica-journal of Iberian and Latin American Economic History, 1, Vol. 33, 123-152.

Djenderedjian, J. 2013. Reseña de Richard-Jorba, Rodolfo (2010). Empresarios ricos, trabajadores pobres. Vitivinicultura y desarrollo capitalista en Mendoza (18501918). Rosario: Prohistoria. En: Población \& Sociedad, 2, Vol. 20, 155-160.

Gelman J. y Santilli D. 2014. "Los salarios y la desigualdad en Buenos Aires, 18101870". América Latina en la Historia Económica, 3, Año 21, 85-115.

Gelman, J. y Santilli, D. 2015. "Salarios y precios de los factores en Buenos Aires, 1770-1880: una aproximación a la distribución funcional del ingreso en el largo plazo". Revista de Historia Económica, 33, Cambridge University Press.

Gelma, J. y Santilli, D. 2016. ¿El paraíso de los asalariados? La canasta de consumo y el nivel de vida de la plebe de Buenos Aires, siglos XVIII y XIX. En Old and New Worlds: the Global Challenges of Rural History. International Conference, Lisbon, 27-30 January.

Gerchunoff, P., Rocchi, F. y Rossi, G. 2008. Desorden y progreso. Las crisis económicas argentinas 1870-1905. Buenos Aires: EDHASA.

Challú, A. E. y Gómez-Galvarriato, A. 2015. "Mexico's real wages in the age of the great divergence, 1730-1930". Revista de Historia Económica, 33, 83-122. 
Dobado-González, R. 2015. "Pre-Independence Spanish Americans: Poor, Short and Unequal... Or the Opposite?" Revista de Historia Económica-Journal of Iberian and Latin American Economic History, 1 (Vol. 33), 15-59.

Llach, L. 2007. "The wealth of the provinces: The rise and fall of the Interior in the political economy of Argentina, 1880-1910". Tesis de Doctorado, Harvard University.

Mateu, A. M. 1995. "Bancos, créditos y desarrollo vitivinícola”. Cuadernos de Historia Regional, 17-18, Universidad de Luján.

Mateu, A. M. 2002. "Aproximaciones a la empresa Arizu: Algunas estrategias de la conformación e incremento del patrimonio societario y familiar (1884-1920)". Quinto Sol. Revista de Historia Regional, 6, Año 6, UNLa Pampa.

Meisel Roca, A. 2008. "Mercados internos, industrialización y finanzas". En E. Ayala Mora (Ed.), Historia general de América Latina: Los proyectos nacionales latinoamericanos, sus instrumentos y articulación. España: Ediciones UNESCOEditorial Trotta.

Olarra Jiménez, R. 1968. Evolución monetaria argentina. Buenos Aires: EUDEBA.

Olguín, P. 2009. Formas de regulación en el mercado vitivinícola (Mendoza, primera mitad del siglo XX). En Segundas Jornadas de la Historia de la Industria y los Servicios. FCE-UBA.

Olguín, P. 2012. "Estado, empresas y regulación. La experiencia de las entidades reguladoras del mercado vitivinícola de Mendoza (Argentina, 1914-1943)”. Revista de Historia Industrial, 49 (año XXI), Universidad de Barcelona.

Olguín, P. E. 2015. "Estado, empresas y desarrollo económico: las empresas públicas agroindustriales en la Provincia de Mendoza". En A. Regalsky y M. Rougier (Dirs.). Los derroteros del Estado Empresario en la Argentina (siglos XIX y XX). Buenos Aires: UNTREF.

Olguín, P. E. 2013a. "La experiencia de una empresa pública en la regulación del mercado vitivinícola de Mendoza: expansión, declinación y privatización de Bodegas y Viñedos Giol”. En M. Rougier (Comp.). Estudios sobre la industria argentina 3. Carapachay: Leguaje Claro Editora.

Olguín, P. E. 2013b. "La intervención del Estado en la industria vitivinícola. El caso de Bodegas y Viñedos Giol (Mendoza, 1954-1974)”. Tesis de Doctorado en Historia, Tandil, FCH-UNCPBA.

Olguín, P. y Mellado, M. V. 2010. "Fracaso empresario en la industria del vino. Los casos de Bodegas y Viñedos Giol y del Grupo Greco. Mendoza, 1974-1989”. Anuario IEHS, 25, UNCPBA.

Parolo, M. P. 2015. "Canastas de consumo y costos de subsistencia en Tucumán durante la primera mitad del siglo XIX”. Revista Población \& Sociedad, 2, Vol. 20, Fundación Yocavil, Tucumán.

Piketty, T. 2014. El capital en el siglo XXI. México: Fondo de Cultura Económica.

Prieto, M. del R. y Chorén, S. B. 1990. "Trabajo y comportamientos familiares. Los sectores populares criollos en una ciudad finisecular. Mendoza, 1890-1900”. Xama, 3, 175-194. 
Prieto, M. del R. y Chorén, S. B. 1991-1992. "El trabajo familiar en el contexto rural de Mendoza a fines del siglo XIX". Xama, 4-5, 212-140.

Richard Jorba, R. 1998. Poder, economía y espacio en Mendoza 1850-1900. Del comercio ganadero a la agroindustria vitivinícola. Mendoza: Facultad de Filosofía y Letras-UNCuyo.

Richard Jorba, R. 2003. "El mercado de trabajo vitivinícola en la Provincia de Mendoza y los nuevos actores. El «contratista de viña»: aproximación a un complejo sistema de empresarios y trabajadores, 1880-1910". Revista Interdisciplinaria de Estudios Agrarios, 18.

Richard Jorba, R. 2012. "Modernización capitalista y pobreza en Mendoza, Argentina. Desarrollo agroindustrial y condiciones de vida de los sectores populares, 18901918". Antitesis, 9, Vol. 5.

Richard Jorba, R. y Pérez Romagnoli, E. 1994. "El proceso de modernización de la bodega mendocina (1860-1915)". Ciclos, 7, UBA.

Salvatore, R. 1986. "Control del trabajo y discriminación: el sistema de contratistas en Mendoza, Argentina, 1880-1920”. Desarrollo Económico, 102, Vol. 26.

Williamson, J. 2002. "Land, Labour and Globalization in the Pre-industrial Thirld World 1870-1940". Journal of Economic History, 62, Vol. 1.

Williamson, J. G. 1999. "Real Wages, Inequality, and Globalization in Latin America Before 1940". Revista de Historia Económica, $\mathrm{N}^{\circ}$ Especial (año XVII), Universidad Carlos III-Centro de Estudios Políticos y Constitucionales. 